\title{
Improving Web-based Civic Information Access: A Case Study of the 50 US States
}

\author{
Irina Ceaparu and Ben Shneiderman \\ Department of Computer Science \& Human-Computer Interaction Laboratory \\ University of Maryland, College Park, MD 20742 \\ irina@.cs.umd.edu, ben@,cs.umd.edu
}

\begin{abstract}
An analysis of the home pages of all fifty U. S. states reveals great variety in key design features that influence efficacy. Some states had excessively large byte counts that would slow users connected by commonly-used $56 \mathrm{~K}$ modems. Many web sites had low numbers of or poorly organized links that would make it hard for citizens to find what they were interested in. Features such as search boxes, privacy policies, online help, or contact information need to be added by several states. Our analysis concludes with ten recommendations and finds many further opportunities for individual states to improve their websites. However still greater benefits will come through collaboration among the states that would lead to consistency, appropriate tagging, and common tools.
\end{abstract}

\section{Introduction}

All fifty states have invested heavily in building informative web sites to serve their citizens, businesses, and visitors. Typical contents include a greeting from the governor, information about state agencies, invitations for businesses to locate in the state, and descriptions of tourist destinations and state parks. The rich variety of state web sites in terms of content, services, design, privacy protection, assistance to users, and other factors suggests that a comparative examination could lead to recommendations for improvement.

Our initial analysis, based on visits to the home pages of all fifty states, was facilitated by a consistent Universal Record Locator (URL) such as this one for Maryland, www.state.md.us. We captured the home page and then explored key components. Size metrics, such as the number of source code bytes, total bytes, and page length, were a natural starting point. Navigation metrics included number of outgoing and incoming links. We also catalogued whether the home page included the governor's picture, state seal, statehouse picture, scenery picture, or map. We recorded whether services such as a privacy policy, online help, and contact information were readily available.
Even these basic measures revealed great variety that would impact citizen access. For example, six states had a total byte count of under $50 \mathrm{~K}$ meaning that the page would load rapidly, even with modem dialups used by approximately $90 \%$ of households in the US. However, the higher range went up to $274 \mathrm{~K}$, which would be substantially slower to load, and well beyond what most guidelines recommend.

A link analysis showed a similar wide range with the number of links ranging from under 20 for two states and over 115 for one state. Evidence is strong that larger numbers of links from home pages of portal web sites produce more rapid and successful location of information. Yahoo.com with over 200 links is a striking example of how broad shallow trees lead to successful web sites. It is true that subjective reaction by new users shows some dislike of link-laden pages, but even their performance is superior when many links are shown in an orderly manner.

Privacy policies were available from 44 states and a search boxes were available from 40 states on their home pages. These features should probably be included on all state home pages. Newer features such as a disabled user access policy, or a more general universal usability policy, should also be considered.

This initial study has already produced insights and useful recommendations. Our first goal will be to disseminate these results and encourage improved practices by all states. Some coordination by way of the National Association of State Chief Information Officers or the National Governors Association might help to promote good web design policies across the states. The second step would be to encourage adoption of consistency guidelines for terminology, contents, URLs for site components, and navigation. A third step would be to encourage agreement on tagging of data to facilitate search across state web sites. For example, if state park facilities (camping, hiking, boating) were tagged, then new web-based services could create regional or national indexes. A fourth step would be development of software 
tools to enable every state to create and maintain their web sites more rapidly and at lower cost, while becoming more complete and consistent.

A much broader extension would be to develop similar strategies for cities, counties, federal agencies, school districts, universities, etc. Any such proposal will produce skeptics who feel such coordination cannot be achieved or that consistency suppresses creativity and distinctiveness. These are legitimate concerns but a long history of similar attempts shows that all parties and users can benefit by appropriate guidelines, which permit individual variation.

\section{Design goals}

E-Government refers to the use by government agencies of information technologies (such as Wide Area Networks, the Internet, and mobile computing) that have the ability to transform relations with citizens, businesses, and other institutions of government. These technologies can serve a variety of different ends: better delivery of government services to citizens, improved interactions with business and industry, citizen empowerment through access to information, or more efficient government management.

Effective online government requires more than expansion of existing web sites and portals. Digital services demand customer-centric interfaces, innovative data and content management, and improved security measures. Builders and maintainers of government web sites should strive to satisfy citizen needs and enable universal usability, while keeping costs reasonable.

Ideally, designers of governmental web sites should be given a set of guidelines and metrics that solve architectural and design problems, as well as lay out requirements for content. A common look achieved through consistent design and navigation facilitates and improves the users' experience with the web site and minimizes the time and effort to access information on similarly laid out web sites.

Navigation is an important factor in designing a web site. The goal is to provide the users with the information they want in the fewest possible steps, and in the shortest time. The navigation of the web site should be structured in a way that does not require users to have knowledge of the hierarchy of the governmental agencies in order to access information and services. However, too often states (and many other organizations) structure their web site according to their organizational plan, rather than the citizens needs. For example, most citizens would not know that information about forests is often with one agency (typically commerce or environment) while parks is with another (typically tourism or recreation). Citizens simply want to know about campgrounds, and don't understand the distinctions that governments make.

Graphics should be a part of any web site. However, the balance between text and graphics should be carefully maintained. In the case of governmental web sites, graphics may be used to convey the "personality" of the state: an image of the biggest tourist attraction or the map and state seal. Designers must however take into consideration the fact that large graphics impose long loading times for pages, especially for users linking to the Internet via modems or slower network connections. Some HTML features like tables can be used to add to the graphic aspect of the pages, as long as they do not interfere with the accessibility guidelines that every web site should comply with (e.g. frames are not recommended).

The byte count of each page of the web site determines the audience that has access to the web site. Faster loading pages will generate larger audiences and greater willingness to return. As page length increases, the amount of scrolling involved increases, leading to the loss of local context and to difficulties in navigation. Shortening pages and linking to related pages also has a large penalty, forcing designers to put high frequency items near the top of pages, produce a compact layout, and reduce the number of jumps.

Governmental web sites offer not only access to information, but also to civic services, such as license application or real estate tax reports. In doing so, state officials must protect an individual's right to privacy when they collect personal information and take responsibility for the accuracy of information provided. Citizens should feel confident that their privacy is protected when using online government services. State officials should also ensure equal opportunity to access the information and services offered by their web sites. Issues like universal usability and accessibility should be carefully considered.

\section{Related work}

A thoughtful study on e-government in the US analyzed 1,680 state and federal government websites for features such as privacy, security, disability access, foreign language access, email responsiveness, and online services [1]. The report concludes that:

- there have been big improvements in access to publications and databases, and in the creation of portals

- more web sites are offering online services

- a growing number of sites are offering privacy and security policy statements 
- a small proportion of sites offer access to the disabled or non-English speakers

- most sites do not allow for website personalization

- progress has been made in state and federal governments creating websites that have more uniform, integrated, and standardized navigational features

- only half of government websites are searchable

Another study of e-government focused on "Planning and Creating a Government Web Site: Learning from the Experience of US States" [2]. This report identified these criteria:

\begin{tabular}{|l|l|}
\hline Criterion & Description \\
\hline Retrieval Time & Time to download page(s) \\
\hline Readability & Use of background colors and texture \\
\hline Flexibility & $\begin{array}{l}\text { Options available to users (text vs. } \\
\text { graphic interface, etc.) }\end{array}$ \\
\hline Semantics & $\begin{array}{l}\text { Coherent use of symbolic or graphic } \\
\text { meaning }\end{array}$ \\
\hline Aesthetics & $\begin{array}{l}\text { Coherent style to help users focus on } \\
\text { content }\end{array}$ \\
\hline $\begin{array}{l}\text { Layout/ } \\
\text { Organization }\end{array}$ & $\begin{array}{l}\text { Context cues: page length, layout, and } \\
\text { typography }\end{array}$ \\
\hline $\begin{array}{l}\text { Advanced } \\
\text { Display Features }\end{array}$ & $\begin{array}{l}\text { Use of image maps, forms, multimedia, } \\
\text { virtual reality, or other }\end{array}$ \\
\hline
\end{tabular}

DeConti claims that the major goals to be achieved through the implementation of a government web site are: - To build a user-friendly place on the Internet available to citizens for access to and dissemination of government information and services.

- To gain the experience necessary to build a foundation for improved access to government information and delivery of services through the use of information technology.

- To promote the country to the rest of the world in a manner that enhances tourism, economic development opportunities and other national or regional interests.

A quantitative analysis of a large collection of expertrated web sites reveals that page-level metrics can accurately predict if a site will be highly rated [3]. The results provide an empirical foundation for web site design guidelines and also suggest which metrics can be most important for evaluation via user studies. The web page metrics computed for the study include:

\begin{tabular}{|l|l|}
\hline \multicolumn{1}{|c|}{ Metric } & \multicolumn{1}{c|}{ Description } \\
\hline Word Count & Total words on a page \\
\hline Body Text \% & $\begin{array}{l}\text { Percentage of words that are body vs. } \\
\text { display text (i.e., headers) }\end{array}$ \\
\hline $\begin{array}{l}\text { Emphasized Body } \\
\text { Text \% }\end{array}$ & $\begin{array}{l}\text { Portion of body text that is emphasized } \\
\text { (e.g., bold, capitalized or near !'s) }\end{array}$ \\
\hline $\begin{array}{l}\text { Text Positioning } \\
\text { Count }\end{array}$ & Changes in text position from flush left \\
\hline $\begin{array}{l}\text { Text Cluster } \\
\text { Count }\end{array}$ & $\begin{array}{l}\text { Text areas highlighted with color, } \\
\text { bordered regions, rules or lists }\end{array}$ \\
\hline
\end{tabular}

\begin{tabular}{|l|l|}
\hline Link Count & Total links on a page \\
\hline Page Size & $\begin{array}{l}\text { Total bytes for the page as well as } \\
\text { elements graphics and stylesheets }\end{array}$ \\
\hline Graphic \% & $\begin{array}{l}\text { Percentage of page bytes that are for } \\
\text { graphics }\end{array}$ \\
\hline Graphics Count & $\begin{array}{l}\text { Total graphics on a page (not including } \\
\text { graphics specified in scripts, applets and } \\
\text { objects) }\end{array}$ \\
\hline Color Count & Total colors employed \\
\hline Font Count & $\begin{array}{l}\text { Total fonts employed (i.e., face }+ \text { size }+ \\
\text { bold }+ \text { italic) }\end{array}$ \\
\hline
\end{tabular}

A global public sector study by Deloitte Consulting and Deloitte \& Touche [4] examines government approaches to service delivery from an enterprise perspective. Their research explores not just how governments combine their people, technology and business strategy to serve citizens, but why they do it, the successes they have achieved and the hurdles they will encounter moving into the e-government era. This report is the second phase of an e-government research project that began with an examination of U.S. state agencies. The scope was then broadened for the second phase to include governments in Australia, Canada, New Zealand and the United Kingdom. In all, 261 government officials participated in the survey.

The Center for Technology in Government, University of Albany, State University of New York is an applied research center [5] devoted to improving government and public services through policy, management, and technology innovation. CTG is an information technology research and demonstration resource for local, state, and federal government, whose projects have generated innovative government practices, solutions to service delivery problems and guidelines for practical use of emerging technologies.

The Civic Resource Group www.civicresource.com is an organization that provides a full range of Internet tools, strategies and solutions to address the specific needs of the civic community. The Civic Resource Group provides independent research and analysis on the use of the Internet and its impact on society. Their research project [6], "Cities on the Internet 2001: E-Government Applied", systematically evaluated the web sites of all cities in the United States with a population of over 100,000 and measured over 70 different variables ranging from information delivery, to technology, e-policies, and online services. The study was conducted to help cities make decisions about how to use the Internet to better serve stakeholders and to help technology and management companies assist cities in their efforts. The report examines 224 U.S. City Government web sites and evaluates how each is using technology for online 
transactions, outreach, service delivery, information exchange, and community building.

NASCIO (National Association of State Chief Information Office) [7] represents state chief information officers and information resource executives and managers from the 50 states, six U. S. territories, and the District of Columbia, with the mission to shape national IT policy through collaborative partnerships, information sharing and knowledge transfer across jurisdictional and functional boundaries. One of NASCIO's main services is StateSearch - a database of state government information links organized by category. The database is searchable and can provide information from 32 categories (e.g. Education Departments and related links for each state).

The States Inventory Project [8], developed by the National Information Infrastructure, provides a single clearinghouse for tracking state, territorial, and provincial information infrastructure strategies and activities. By providing a resource for jurisdiction-by-jurisdiction comparative analyses, the States Inventory Project helps the states, territories, and provinces efficiently develop their own advanced information infrastructures. This resource is shared and maintained by policy makers, telecommunications experts, and other interested parties. The Project provides a searchable database of: government uses and regulations of NII/advanced telecommunications, local and state projects related to the use of the NII and advanced telecommunications for education, telemedicine, and related areas, strategic plans for the use and deployment of the NII and advanced telecommunications, and other related government activities. The database can be accessed by state or by category.

Other sources of insight for designers comes from organizations that provide guidelines for building web sites including: The World Wide Web Consortium's Web Accessibility Initiative

(WAI) (http://www.w3.org/WAI/, The US National Cancer Institute's Research-Based Web Design \& Usability Guidelines (http://www.usability.gov/guidelines/), The Universal Usability Guide (http://universalusability.org/index.html, IBM Ease of Use: $\quad$ Web $\quad$ Design Guidelines http://www3.ibm.com/ibm/easy/eou ext.nsf/Publish/572 PrintView

\section{Methodology and Results}

We studied the 50 states web site home pages Www.state.[**].us, and recorded the design properties and service features listed in Table 1. The metrics were selected to reflect a number of features that are important to the design of governmental websites.

\begin{tabular}{|l|l|l|l|l|}
\hline $\begin{array}{l}\text { Size } \\
\text { metrics }\end{array}$ & $\begin{array}{l}\text { Navigation } \\
\text { metrics }\end{array}$ & Graphics & Services & Other \\
\hline $\begin{array}{l}\text { source } \\
\text { bytes }\end{array}$ & $\begin{array}{l}\text { \# of outgoing } \\
\text { links }\end{array}$ & $\begin{array}{l}\text { governor } \\
\text { picture }\end{array}$ & $\begin{array}{l}\text { privacy } \\
\text { policy }\end{array}$ & tables \\
\hline $\begin{array}{l}\text { gif } \\
\text { bytes }\end{array}$ & $\begin{array}{l}\text { \# of incoming } \\
\text { links }\end{array}$ & state seal & $\begin{array}{l}\text { universal } \\
\text { usability }\end{array}$ & frames \\
\hline $\begin{array}{l}\text { largest } \\
\text { gif } \\
\text { bytes }\end{array}$ & $\begin{array}{l}\text { navigation } \\
\text { style \& } \\
\text { consistency }\end{array}$ & $\begin{array}{l}\text { statehouse } \\
\text { picture }\end{array}$ & $\begin{array}{l}\text { contact } \\
\text { info }\end{array}$ & search \\
\hline $\begin{array}{l}\text { total } \\
\text { bytes }\end{array}$ & & $\begin{array}{l}\text { scenery } \\
\text { picture }\end{array}$ & help & $\begin{array}{l}\text { wea- } \\
\text { ther }\end{array}$ \\
\hline & & map & \multicolumn{2}{|l}{} \\
\hline
\end{tabular}

Table 1: Design properties and service features that were studied

\section{Byte count}

The time it takes for a page to download is important [2] for making it easily accessible by every citizen interested in accessing online state services. The first analysis that was done was the byte count of the source of the home pages, followed by a count of the number of bytes of the images that appear on the home pages and a count of the number of bytes of the largest image (Figure 1). The outliers were the state of Vermont with the smallest total byte count and the state of Washington with the largest total byte count. Also, the state of Washington proved to have the biggest image (in number of bytes).

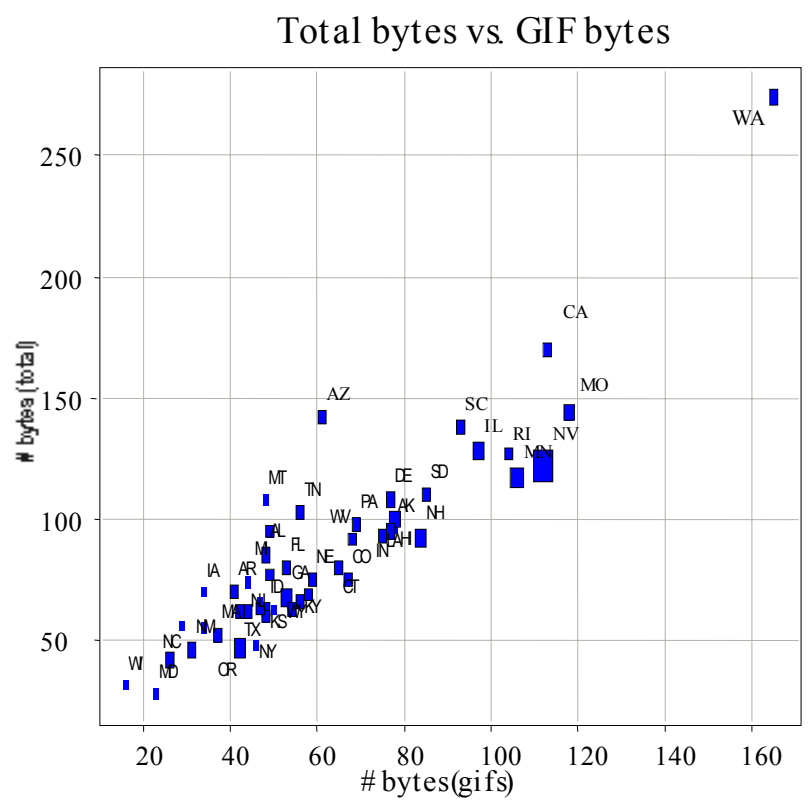

Figure 1: Byte count - The Spotfire display shows Total kilobytes vs. GIF kilobytes for each state. The size of each marker reflects the number of bytes in the largest gif. 


\section{Link count}

The number of incoming and outgoing links of a web site reflects its usage and the amount of services it offers. The second analysis we have done involves the number of outgoing links for the home page and the number of incoming links for the whole web site of each state. The states' web sites fall in two big categories: link-heavy and link-light. The number of outgoing links ranges from 10 to 115 . The way these links are grouped also varies from state to state. Some states group them categorically (Yahoo style), others group them alphabetically. The outliers were: the states of Delaware and Nevada with the smallest number of links and the state of Vermont with the largest number of links. The count of incoming links was done using the AltaVista advanced search feature. In this case, the outliers were the state of Washington with 627 incoming links and the state of Tennessee with 72138 incoming links (Figure 2).

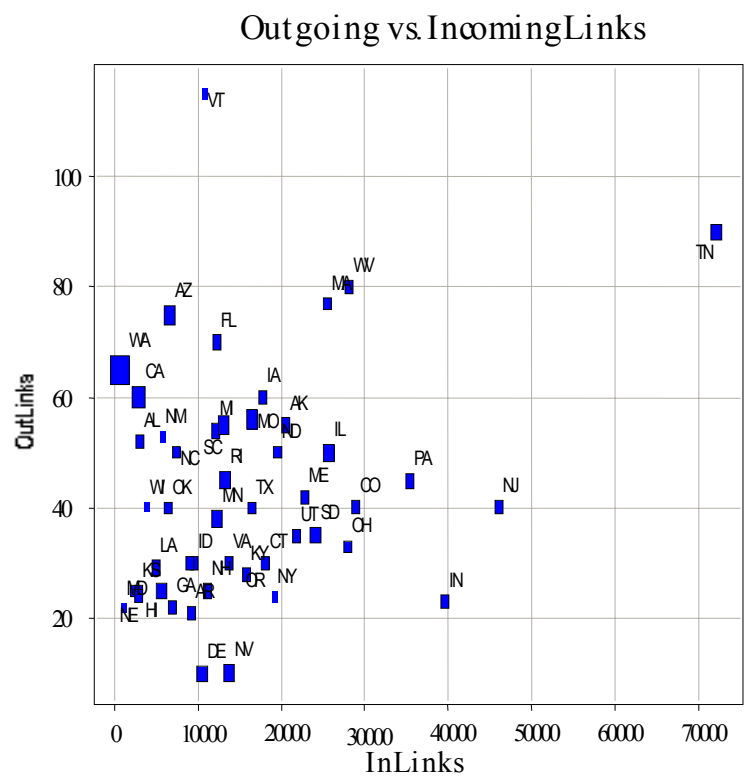

Figure 2: Link count - The Spotfire display compares the number of outgoing and incoming links for each state, where the size corresponds to the total number of bytes.

\section{Navigation}

In terms of navigation, our analysis focused on the consistency of the navigation style. Navigation bars should be present on all websites, in order to allow quick access through the entire site, particularly for those web sites with large amounts of content. However, only a few states (9) use a navigation bar throughout the entire web site. Some of them have a navigation bar just on the first two-three levels of navigation. But most of the states do not use a navigation bar at all (26 out of 50) (Figure 3 ).

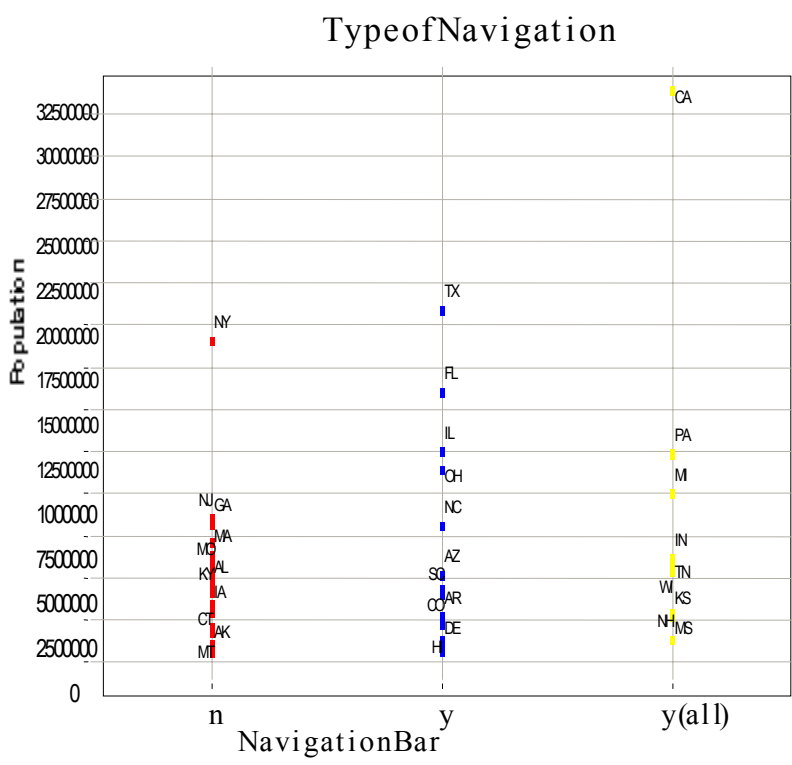

Figure 3: Navigation type - The Spotfire display shows 3 types of navigation (none, use on home page, use throughout web site). The y-axis represents the population for each state.

\section{Graphical features}

Another category of features we have analyzed is related to the graphical aspect of the home page. We looked at the presence or absence of the following 5 features: governor's picture, state seal image, statehouse image, state map image and scenery image. More than half of the states display a picture of the governor on the home page (Figure 4). On the other hand, more than half of the states do not display a state seal image or a statehouse image on the home page. As for the map of the state, there is a 50-50 split between the number of states that do show their map and the number of states who don't. Finally, most of the states (over 70\%) display a scenery image on their home page.

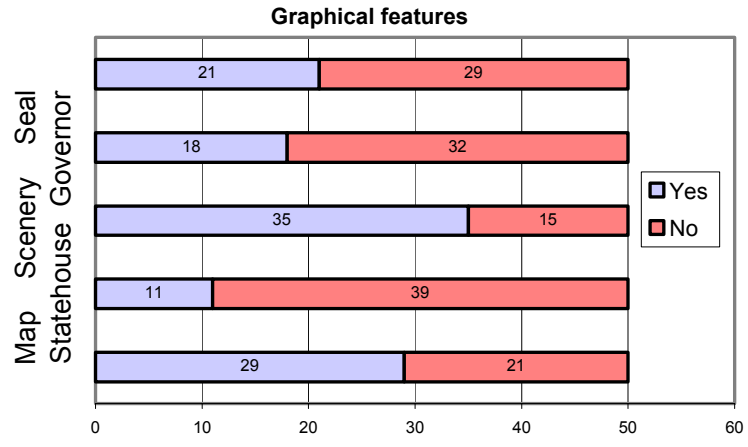

Figure 4: Presence of graphical features: Map, Scenery, Seal, Statehouse, Governor picture 
Another feature that we studied is the presence of contact information, and the type of contact information (email, full email+address+phone, none) provided (Figure 5). More extended contact information is a benefit for citizens.

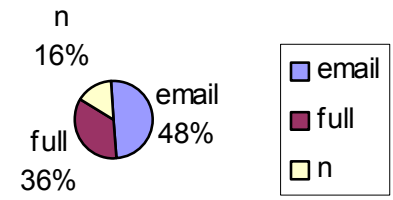

\section{Figure 5: Presence of contact information}

The use of the Internet by governments and organizations has raised concerns about the privacy of web browsing activities ([1], [4]). Therefore, the presence of a clearly stated privacy policy is a requirement for all web sites, and especially for governmental ones. The result of our analysis is that most states' web sites do provide a privacy policy. However, there are a few states (20\%), which do not address this issue (Figure 6).

Privacy, Tables, Frames, Search

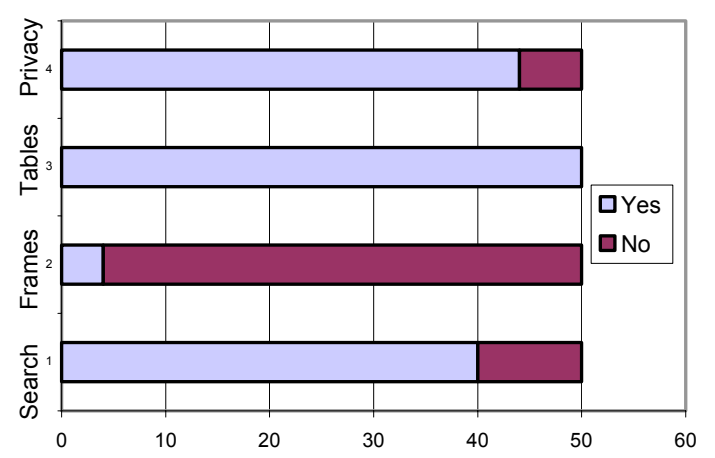

Figure 6: Presence of privacy policy, tables, frames and search feature. All of them make use of tables, but only a few make use of frames. Most of sites provide privacy policy and a search box.

The issue of universal access to information should also be addressed by the constructors of a governmental web site. We analyzed how many states' web sites display a universal usability/accessibility statement on the home page. The percentage is $38 \%$ (Figure 7).

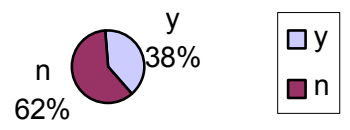

\section{Figure 7: Presence of Universal usability/ Accessibility policy}

\section{Initial recommendations}

Our analysis of the features and services provided by the states' web sites suggest that a common template would lead to greater simplicity, enhanced consistency, quicker search and greater ease of use.

Our evaluation leads to these initial recommendations to the webmasters of the states' web sites:

1) keep number and size of images small (maximum number of image bytes $<50 \mathrm{~K}$ ) in order to reduce the download time and therefore make it easily available for users with slow connections and low bandwidth

2) avoid using frames in order to comply with the universal accessibility rules

3) provide a search box/button on the home page in order to facilitate access to information hidden on the lower levels of the site hierarchy

4) use a broad and shallow menu tree (30-80 links on the home page)

5) use a navigation bar and make it consistent throughout the entire web site in order to make navigation easier and more predictable

6) display clearly stated privacy policy and universal usability statement on the home page

7) provide extensive contact information of appropriate officials by email, phone, fax, etc.

8) offer help and feedback for every action that the user might take

9) include in the links on the top page at least the following 10 categories that were found on most of the web sites: Government (40), Tourism(40), Business(33), Education(27), Employment(26), Legislature(17), Online Services(11), Health(11), Citizens(11), Living (9), Tax (5) 10) achieve consistency in naming links. For example, for the governor web page, states might chose a common name, rather than variations such as:

MD www.gov.state.md.us. $T X: W w w . g o v e r n o r . s t a t e . t x . u s$ $\mathrm{OH}$ www.state.oh.us/gov/AR: www.state.ar.us/governor Consistent names for frequently used services such as tourism, education, business, etc. would also be beneficial. 


\section{Conclusion and future work}

The Web environment offers state governments the opportunity to deliver information and services, to enhance communication to and among its citizens, and to provide means for citizens to interact with government officials. Political scientists, sociologists, management researchers, and social critics have speculated about and encouraged electronic services that might benefit citizens [9-14]. In response, state administrators have taken up the challenge to produce web sites with information and services. Early responses are enthusiastic, but a more mature phase will lead to greater concerns about quality and calls for sober cost benefit analyses. Goals will be sharpened and metrics of success debated.

This paper presents a set of initial recommendations for information delivery and Web site design that will improve the Web presence of the local government of each of the 50 US states and will better meet the demands of the citizens for public access to government information. The guidelines based on the analysis of the web sites of the 50 states offer a model of good practice for the design of the sites, in terms of consistency in structure, ease of navigation and accessibility.

In addition to improving the quality of each state's Web site, even greater benefits will come when the states coordinate to choose consistency site names, terminology, navigation, etc. Then common strategies for tagging information will enable more refined searches and innovative inter-state indexes, such as lists of all parks in a region organized by services such as camping, boating, or fishing. Eventually software tools could be developed jointly by the states to enable all states to collect and maintain the information in more timely, complete, and economical ways. Another opportunity for collaboration would be to develop citizen surveys and automaticallycollected metrics for usage, success, and benefit. Then state administrators will have the information they need to guide future decisions on web development projects.

Acknowledgements: We appreciate partial support from National Science Foundation grant for Information Technology Research (\#0086143).

\section{References}

[1] West, D., State and Federal E-Government in the United States, Brown University, September 2001. http://www.insidepolitics.org/egovt01us.html

[2] DeConti, L., Planning and Creating a Government Web Site: Learning from the Experience of US States, Information Systems for Public Sector Management Working paper Series, University of Manchester, UK, 1998. http://idpm.man.ac.uk/idpm/ispswpf2.htm
[3] Ivory, M. Hearst, M. and Sinha, R., Empirically Validated Web Page Design Metrics, ACM SIGCHI'01 Conference: Human Factors in Computing Systems, 5360, ACM, New York, 2001.

[4] Deloitte Consulting and Deloitte \& Touche, At the Dawn of E-Government, a global public sector study by Deloitte Consulting and Deloitte \& Touche, 2000. http://www.dttus.com/PUB/ggovt/e-gove $1 . p d f$

[5] The Center for Technology in Government, University of Albany, State University of New York, last accessed:

February 4th, 2002.

http://www.ctg.albany.edu/resources/toc.html

[6] The Civic Resource Group, last accessed: February 4th, 2002.

http://www.civicresource.com/downloads/EGovExecutive Brief.pdf

[7] NASCIO (National Association of State Chief Information Office) web site, last accessed: February 4th, 2002 http://www.nascio.org

[8] States.org - The States Inventory Project, last accessed: February 4th, 2002. http://www.states.org

[9] Wilhelm, Anthony G., Democracy in the Digital Age: Challenges to Political Life in Cyberspace, Routledge, New York and London, 2000.

[10] Putnam, Robert, Bowling Alone: The Collapse and Revival of American Community, Simon \& Schuster, New York. 2000.

[11] Fountain, Jane, Building the Virtual State: Information Technology and Institutional Change, Brookings Institution Press, Washington, DC, 2001.

[12] Levine, Peter, The Internet and civil society, Report from the Institute for Philosophy \& Public Policy 20, 4, 2000.

http://www.puaf.umd.edu/IPPP/reports/vol20fall00/vol20. html

[13] DiMaggio, P., Hargittai, E., Neuman, R., and Robinson, J., The Social Implications of the Internet, Annual Review of Sociology 27, 307-336, 2001. http://www.princeton.edu/ eszter/ARS-Internet.pdf

[14] Dawes, Sharon, Bloniarz, Peter, Kelly, Kristine, and Fletcher, Patricia, Some assembly required: Building a digital government for the $21^{\text {st }}$ century, March 1999. http://www.ctg.albany.edu/research/workshop/dgfinalrepo rt.pdf 